\title{
POLÍTICAS DE DESENVOLVIMENTO DA PESCA E AQUICULTURA: CONFLITOS E RESIS- TÊNCIAS NOS TERRITÓRIOS DOS PESCADORES E PESCADORAS ARTESANAIS DA VILA DO SUPERAGÜI, PARANÁ, BRASIL.
}

\section{Fishery and aquaculture development policies: Conflicts and resistances in the territories of artisanal fishers of Superagui village, Paraná, Brazil}

\author{
Mercedes Solá Pérez \\ UFPE, Recife, Pernanbuco, Brasil. \\ mercedessolap@hotmail.com \\ Jorge Ramón Montenegro Gómez \\ UFPR, Curitiba, Paraná, Brasil. \\ jorgemon@ufpr.br
}

Artigo recebido em 21/10/2012 e aceito para publicação em 29/10/2013

RESUMO: O trabalho trata sobre os conflitos e as resistências provocados pela aplicação de políticas públicas de desenvolvimento no território de vida dos pescadores e pescadoras artesanais da Vila do Superagüi. São especificamente, políticas de desenvolvimento referidas à pesca e à aquicultura. Estes pescadores artesanais que já se viram atingidos nos seus territórios pela política de desenvolvimento sustentável através da instalação do Parque Nacional do Superagüi que limita o uso que podem fazer da natureza em terra, sofrem também com as imposições da política de pesca e aquicultura. Os pescadores/as artesanais hoje empurrados a especializar-se na pesca têm conflitos nos seus territórios de vida devido à política de modernização da pesca e da aquicultura que incentiva a pesca industrial, a incorporação de equipamentos modernos e estabelece áreas aquícolas. A leitura da realidade em campo junto a uma leitura do desenvolvimento através de referências do pós-desenvolvimento permite identificar que essa política responde a interesses externos, excluindo os pescadores artesanais, negando seus modos tradicionais de reproduzir a vida, expropriando-os dos territórios que tradicionalmente ocupam e mercantilizando sua vida. Em função desses conflitos, a comunidade cria resistências organizando-se como movimento social, reivindicando assim, seus territórios de vida.

Palavras-chave: Pescadores e pescadoras artesanais; Conflitos e resistências; Políticas de pesca e da aquicultura; Territórios de vida.

ABSTRACT: This investigation is about the conflicts and resistances that the application of developmental public policies is generating in the territories of the artisanal fishers of the Superagüi Village. These are development policies related to fishery and aquaculture. This artisanal fishers that were already affected in their territories by the sustainable development policies with the installation of the Parque Nacional do Superagüi that's already limiting their natural assets, are also suffering from the impositions of the fishery and aquaculture policy. The fishers that are currently pushed to specialize in fishery are in conflict in their living territories because the policies of modernization of fishery and aquaculture are pushing to industrial fishing, to incorporate modern equipment and to establish aquaculture areas. The reading of the field's reality along

DOI: $10.1590 / 1982-451320140103$ 
Políticas de desenvolvimento da pesca e a aquicultura: Conflitos e resistências nos territórios dos pescadores e pescadoras artesanais da Vila do Superagüi, Paraná, Brasil

Mercedes Solá Pérez, Jorge Ramón Montenegro Gómez

with a reading of the development from references of the post-development shows that those policies are attached to foreign interests, excluding the artisanal fishers, denying their traditional ways of reproducing life, taking away the lands that they traditionally occupy and commodifying their life. Based on these conflicts, the community creates resistances as a social movement and demanding their living territories. Keywords: Artisanal fishers; Conflicts and resistances; Fishery and aquaculture development policies; Living territories.

\section{INTRODUÇÃO: CONTEXTO DE POLÍTICAS DE DESENVOLVIMENTO}

Desde a década de 1970 quando começaram a chegar à Ilha as políticas de conservação da natureza com a inscrição da Ilha do Superagüi como Patrimônio Natural e Histórico pela Divisão do Patrimônio Histórico, Artístico e Cultural do Paraná, e mais especialmente a partir de 1989, com a criação do Parque Nacional do Superagüi, os pescadores e pescadoras artesanais da Vila do Superagüi se vêm expulsos dos seus territórios de vida. Essa decisão, inserida dentro das políticas de desenvolvimento sustentável, resulta em proibições pela sobreposição de territórios. Tanto a política de desenvolvimento sustentável como a de desenvolvimento da pesca e aquicultura, que difunde a integração dos pescadores artesanais na dinâmica da pesca industrial provocam um impacto no território de vida dos pescadores e pescadoras da Vila do Superagüi, negando-o a seus habitantes tradicionais e dedicando-o a formas de acumulação que os subordinam.

Antes disso, a Vila do Superagüi era uma área periférica, com pouca utilização de tecnologia e longe da chamada modernidade. Era nesse contexto de desenvolvimento desigual e combinado que a vida dos pescadores e pescadoras artesanais da Vila do Superagüi ocorria de maneira relativamente autônoma. Era um modo de vida específico que não separava a cultura da natureza, o trabalho era realizado em estreita relação com a satisfação das necessidades básicas, era uma vida compreendida como totalidade. As atividades produtivas - caça, pesca, criação de animais, roçado, coleta de plantas medicinais, lenha, cipó, etc. - eram conjugadas.

Mas a instalação do Parque Nacional do Superagüi proibiu qualquer atividade dentro da área que se encontrara em sobreposição com o território dos pescadores e pescadoras da Vila do Superagüi, criando-se assim uma restrição de uso da natureza, do seu território de vida e passando-se a uma espe- cialização para a atividade da pesca. A partir desse momento, as políticas de pesca e aquicultura tomam especial importância para essa comunidade e começam os conflitos com a atividade artesanal realizada pelos pescadores da Vila.

Neste sentido, propomos neste texto analisar os conflitos e as resistências que geram a aplicação de políticas públicas de desenvolvimento do setor de pesca e aquicultura no território de vida dos pescadores e pescadoras artesanais da Vila do Superagüi. Para isso, identificamos os modos de vida dos pescadores e pescadoras artesanais da Vila do Superagüi, analisamos a inserção das políticas de desenvolvimento no Brasil, descrevemos brevemente as políticas de desenvolvimento do setor pesqueiro, mostramos os conflitos territoriais que decorrem dessas políticas setoriais e finalizamos apresentando as resistências dos pescadores e pescadoras artesanais do Superagüi diante do avanço do capital.

\section{MODOS DE VIDA DOS PESCADORES E PES- CADORAS DA VILA DO SUPERAGÜI: PERMA- NÊNCIAS E MUDANÇAS}

A Ilha do Superagüi, localizada no litoral norte do estado do Paraná, próxima ao estado de São Paulo, é povoada historicamente por comunidades que sempre exerceram a agricultura, a coleta e a pesca. Pertence ao município de Guaraqueçaba, faz parte do Complexo Estuarino-Lagunar de Iguape-Cananéia e se situa no domínio da Floresta Atlântica, o que implica em grande biodiversidade, com presença de mangue no estuário e todos os estratos de vegetação na terra (VIVEKANANDA, 2001). Ao longo dela, há seis comunidades, sendo a Vila do Superagüi (Figura 1) - foco desta pesquisa - aquela que concentra maior quantidade de pessoas. Segundo dados de campo, na Vila vivem em entorno de 280 famílias, isto é, umas 900 pessoas aproximadamente. 
Figura 1 - Localização da Vila do Superagüi, Ilha do Superagüi, Município de Guaraqueçaba-PR

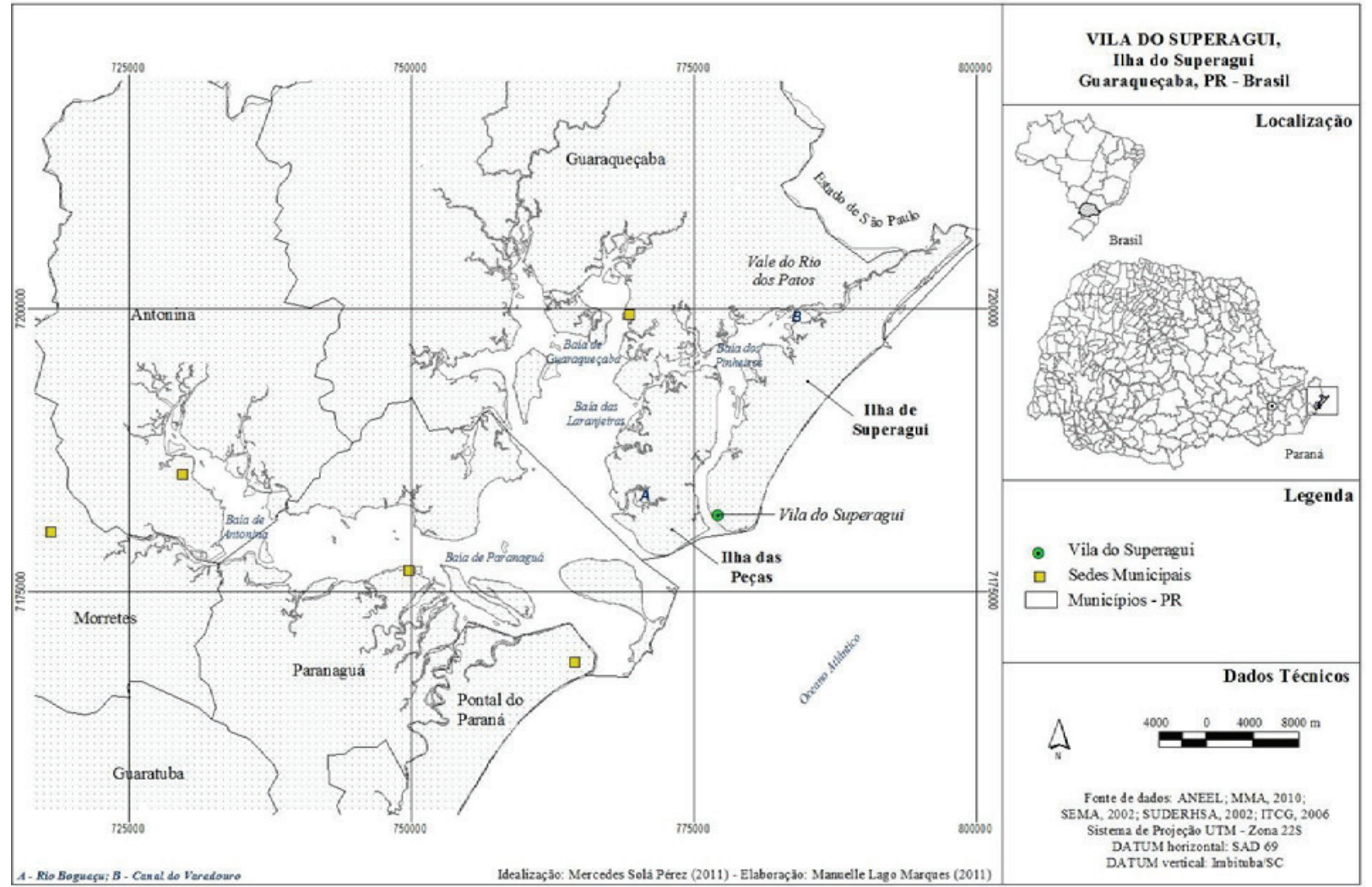

Org. da autora. Elaboração: Manuelle Lago Marques.

Antes regulados pelo tempo da natureza - e não da produção -, os pescadores trabalhavam o necessário para comer e, às vezes, vender o excedente pescado (SILVA, 2004). Também realizavam seu trabalho através de uma relação estreita entre natureza e cultura, seguindo um modo específico de reproduzir a vida baseado na pesca (parati, cação, dourado, corvina, robalo, camarão sete barbas, camarão branco e tainha especialmente), agricultura itinerante (arroz, feijão, café, mandioca, batata, inhame, milho, etc.) e a caça (macuco, tatu e paca); preparavam a farinha de mandioca; faziam o corte e uso de diversos materiais para construção de utensílios, lenha e ferramentas diversas, canoas e suas próprias casas; utilizavam plantas nativas medicinais; e tocavam o fandango comemorando o trabalho coletivo bem sucedido da colheita.

Porém as restrições criadas pela instalação do Parque Nacional (Decreto ${ }^{\circ} 97.688$ de 1989 e ampliado em 1997 através do Decreto 9513) impõem a necessidade de pescar mais, propiciando uma maior comercialização para comprar aquilo que antes era cultivado, caçado ou criado com as próprias mãos, passando a especializar-se na atividade da pesca.

A pesca em toda a Ilha do Superagüi é artesanal e têm diferentes artes de acordo com a comunidade, estuarina ou marítima, sendo que especificamente os pescadores e pescadoras da Vila pescam predominantemente em mar aberto. As características da pesca artesanal estão relacionadas à atividade próxima à costa, com embarcações de pequeno porte e pesca com pouca duração de tempo, em torno de seis horas (CORRÊA, 2003).

O costume dos pescadores da Vila do Superagüi é sair em três ou quatro homens que vão dividir o pescado, depois levar a produção para as mulheres beneficiarem, isto é, limparem e descascarem dando maior valor no ato da comercialização, vendendo aos atravessadores que o transportam para Paranaguá ou, inclusive para São Paulo. Cabe ressaltar que os pescadores sempre reservam uma parcela da produção para consumo da família. 
Políticas de desenvolvimento da pesca e a aquicultura: Conflitos e resistências nos territórios dos pescadores e pescadoras artesanais da Vila do Superagüi, Paraná, Brasil

Mercedes Solá Pérez, Jorge Ramón Montenegro Gómez

Em campo, identifica-se também a necessidade dos pescadores e pescadoras da Vila de realizarem outras atividades não relacionadas diretamente com a pesca ou com as atividades tradicionalmente realizadas, como modo de complementar a renda. Essas atividades são relacionadas ao turismo e aos serviços gerais como construção, limpeza de casas, etc., seja na ilha ou fora. Neste caso, vão trabalhar nas cidades próximas, mesmo que por períodos determinados de tempo como, por exemplo, na época do defeso de camarão (entre 1 de março e 31 de maio).

A especialização na atividade de pesca implicou em um contato maior com as políticas e legislações deste setor. Políticas que, como veremos a seguir, implicam na modernização da atividade da pesca e mesmo no incentivo à conversão para a aquicultura, devido à escassez dos estoques pesqueiros por pesca predatória especialmente industrial.

\section{O DESENVOLVIMENTO COMO MODELO DE SUCESSO: ÂNCORAS GERAIS DAS POLÍTI- CAS PESQUEIRAS}

O desenvolvimento do setor da pesca no Brasil se insere em um contexto mais amplo em que a ideia de desenvolvimento aparece como receita para o sucesso, caminho natural para o progresso e a melhora de vida. Essa ideia começa a ser imposta na década de 1950 desde os países desenvolvidos, especialmente EUA, através dos diversos organismos de controle - ONU, FMI, BM - para os países subdesenvolvidos ou, hoje chamados, países em desenvolvimento.

No ano de 1949, período no qual está já instalado o processo de substituição de importações no Brasil (1930-1960) e, portanto de modernização, se forja uma divisão na esfera mundial. A mesma é determinada pelo presidente eleito em EUA, Harry S. Truman, no discurso de sua investidura. Nesse discurso, o mundo ficou dividido não somente entre o socialismo ao estilo da União Soviética e o capitalismo do american way of life, mas entre países desenvolvidos e subdesenvolvidos. A divisão foi de tal forma naturalizada que implicou na homogeneização de diversas formas de organização social e em um único caminho para o progresso, o desenvolvimento (ESTEVA, 2000).
O desenvolvimento, ao longo das décadas, foi adquirindo diversos adjetivos - econômico, social, humano, local, sustentável - que na prática significaram a continuação de um modelo de modernização, imposição e dívidas permanentes para os países em desenvolvimento (ESTEVA, 2000; LATOUCHE, 2007).

O Brasil, após os governos que acompanharam um cenário internacional de corte mais desenvolvimentista até os anos de 1970, foi sendo incorporado à onda neoliberal a partir dos últimos anos da ditadura militar.

O neoliberalismo, atrelado aos ajustes estruturais que marcariam toda uma época conhecida como década perdida, impõe um processo de desregulamentação, com a destruição dos serviços públicos, o desmantelamento dos sistemas de proteção social, a consequente poluição e destruição dos ecossistemas por falta de controle, o enfraquecimento dos Estados-Nação pela abertura comercial gerando o aumento do poder das empresas multinacionais e reduzindo a intermediação dos estados nacionais perante o mercado (SVAMPA, 2009).

Continua também em aumento a dívida criada no passado em prol do desenvolvimento que os programas de ajuste estrutural não conseguiram reduzir. O que implica em pobreza e precarização da vida da maioria da população, em diminuição dos territórios dos camponeses pela expansão agrícola, especialmente de monocultivos, na adequação do trabalho formal dentro de marcos de empregabilidade flexível, com contratos sempre provisórios, e num sonho de progresso que nunca chega.

O neodesenvolvimento, processo identificado desde começos da década de 2000, caracteriza-se: pela criação/manutenção de políticas de expansão do capital através de investimentos em commodities e estruturas que facilitem a circulação dos mesmos, isto é, conservando medidas neoliberais; pelas políticas de transferência de renda, que não passam de ser assistencialistas e parciais, fazendo com que os índices de pobreza diminuam e; pelo acesso facilitado a créditos, de maneira que o mercado se mantenha movimentado pelo consumo. Estas políticas significam um mix de políticas neoliberais com algumas políticas keynesianas, que caracterizam o neodesenvolvimento dos dois governos de Luiz Inácio Lula da Silva (2003-2006 e 
2007-2010) e se firmam no governo de Dilma Roussef (2011-atualidade) (IHU, 2009).

Esse panorama do que significam as políticas públicas de desenvolvimento para a população permite identificar que o caminho do sucesso é cheio de exclusão, uma racionalidade única que não permite a vida a partir de outras lógicas não capitalistas e é neste sentido, que no próximo item realizamos uma leitura crítica das políticas de desenvolvimento da pesca.

\section{POLÍTICAS DE DESENVOLVIMENTO DA PESCA E AQUICULTURA}

Desde a década de 1960 - quando da criação da Superintendência de Desenvolvimento da Pesca (SUDEPE) sob as ordens do Ministério de Agricultura - as políticas de pesca têm sido propostas para promover a modernização e a industrialização, ou seja, o desenvolvimento do setor, no marco das políticas desenvolvimentistas da época. Os incentivos promovidos durante duas décadas propiciaram a expansão das capturas, o que implicou no declínio dos estoques explorados. No final da década de 1980, em plena onda neoliberal, a SUDEPE é extinta, passando as funções do setor ao Instituto Brasileiro do Meio Ambiente e Recursos Naturais Renováveis - IBAMA. Nesse intervalo entre a década de 1990 e 2000 não se identificam políticas significativas no setor pesqueiro, mas nota-se um recuo na produção da pesca devido à exploração exacerbada do recurso (CARDOSO, 2009).

A partir de 2003, as políticas do setor são criadas e dirigidas pela Secretaria Especial de Pesca e Aquicultura da Presidência da República (SEAP-PR) e desde 2009 pelo Ministério de Pesca e Aquicultura (MPA). As políticas do setor nessa última década são especialmente voltadas ao incentivo à produção aquícola, seja continental ou marinha.

Em 2009, no contexto da SEAP-PR, o então presidente da Nação, Luis Inácio Lula da Silva, iniciou o Plano de Desenvolvimento Sustentável "Mais pesca e aquicultura" com projeção até 2011. As linhas de ação do Plano são referidas a: promoção de créditos, instalação de infraestruturas, modernização da frota, assistência técnica e extensão para pesca e aqüicultura, formação profissional, incentivo ao associativismo, subvenção do óleo diesel, incentivo ao consumo, mo- nitoramento e controle da atividade, desenvolvimento da aqüicultura, gestão estratégica de informação, fortalecer a participação do Brasil na política internacional de pesca e aqüicultura (MPA, 2011).

Este Plano segue em vigência junto ao MPA e com o aval e incentivo da FAO - Food and Agriculture Organization - agência especializada da ONU - Organização das Nações Unidas. A FAO, criada em 1945, busca "aumentar os padrões de vida e os bens agrícolas" e pesqueiros, o que hoje se leva a cabo pelo lema da segurança alimentar e o combate à pobreza, seguindo um modelo moderno e industrial. Nesta linha, os incentivos do Plano "Mais pesca e aquicultura" são especialmente para potencializar as commodities da aquicultura. Os investimentos promovidos são para este subsetor e para a pesca oceânica.

Neste sentido, o MPA, desde o ano de 2009, tem aberto editais para seleção de pessoas físicas ou jurídicas com o objetivo de cessão de áreas para instalação de parques aquícolas. Seguindo a Instrução Normativa Interministerial $\mathrm{n}^{\circ} 1$, de 10 de outubro de 2007, o MPA licita a cessão de uso de espaços referentes a corpos d'água de domínio da União. Esses parques são propostos tanto em áreas de reservatórios de Usinas Hidrelétricas, Pequenas Centrais Hidrelétricas ou áreas de baias. Em 2009, as áreas licitadas foram predominantemente de Mato Grosso, em 2010 foram distribuídas entre os estados de Pernambuco, Bahia, Goiás, São Paulo, Santa Catarina e Paraná (MPA, 2011).

No caso do litoral paranaense, em 2010 foram autorizadas por cessão onerosa, isto é entregues em mãos privadas que devem pagar pelo uso e por período tempo determinado: uma área aquícola de 4,48 hectares e outra de 1,9136 hectares na Baía das Laranjeiras e uma área aquícola de 1,1845 hectares na Baía dos Pinheiros. A Portaria $N^{\circ} 58$ de 2011 outorga o uso das três áreas por um período de 20 anos ao Instituto Mar e Vida. Esses parques aquícolas possivelmente sejam utilizados para criação de ostras já que estão localizados nas Baías das Laranjeiras e dos Pinheiros, áreas de mangue que permitem um bom cultivo das mesmas. Essas baías formam parte do Complexo Estuarino-Lagunar de Iguape-Cananéia, uma das mais importantes áreas de mangue conservado (ICMBIO, 2011), no entanto, não formam parte do Parque Na- 
Políticas de desenvolvimento da pesca e a aquicultura: Conflitos e resistências nos territórios dos pescadores e pescadoras artesanais da Vila do Superagüi, Paraná, Brasil

Mercedes Solá Pérez, Jorge Ramón Montenegro Gómez

cional do Superagüi ainda estando próximas, fazem parte da APA de Guaraqueçaba.

As políticas de desenvolvimento que promovem como modelo a pesca industrial geram, além da homogeneização sociocultural, a sobrepesca de algumas espécies, a destruição de ecossistemas de alta produtividade e a redução do pescado situado junto à costa (BORGES, 2007; CARDOSO, 2001). Trata-se de uma questão ligada a um único setor, a pesca, mas que segue o mesmo modelo de desenvolvimento que impõe o capital para sua reprodução de forma geral desde os finais dos anos 1940, implicando em conflitos importantes nos âmbitos de sociobiodiversidade, como é o caso dos pescadores e pescadoras da Vila do Superagüi.

\section{CONFLITOS TERRITORIAIS COMO CONSE- QUÊNCIA DAS POLÍTICAS DE DESENVOLVI- MENTO DA PESCA E AQUICULTURA}

Os conflitos territoriais que enfrentam os pescadores e pescadoras artesanais com uma pesca mercantilizada e em maior escala, se referem a que esses processos de modernização que as políticas públicas promovem, mudam a lógica do trabalho e da produção, os modos de vida tradicionais e, portanto, da identidade.

Os incentivos fiscais da SUDEPE a partir dos anos 60 para industrialização da pesca promoveram a degradação dos recursos naturais (CARDOSO, 2009), a concentração da riqueza e a expropriação dos pescadores artesanais (LOBO COSTA, 2007).

As políticas de modernização provocam também conflitos internos no setor, entre os pescadores artesanais e a pesca industrial. "Os conflitos internos à pesca resultam da competição pelos recursos entre diferentes grupos de interesse. Em particular, o desenvolvimento da pesca empresarial na plataforma costeira paranaense gerou uma série de conflitos com a pesca de menor escala" (ANDRIGUETTO FILHO, 1999, p. 210).

Embora tais grupos não tenham limites precisos, os pescadores paranaenses conflitam com os grandes barcos, sobretudo catarinenses, que fazem pesca de arrasto, pescando camarão rosa e sete barbas, ou utilizam portas e parelhas, bem mais pesadas que aquelas dos pescadores artesanais, varrendo o fundo do mar. Segundo os pescadores de Paraná, os barcos da pesca industrial degradam o meio ambiente acabando com a biodiversidade e não respeitam o limite de três milhas da costa reservados para os pescadores artesanais (ANDRIGUETTO FILHO, 1999).

A diferença entre o barco industrial e o artesanal, segundo o relato de um pescador da Vila do Superagüi, é que as duas portas dos barcos dos pescadores artesanais pesam juntas, em torno de 24 quilos e as da pesca industrial chegam a pesar aproximadamente 150 quilos cada uma. Isso faz com que as portas do barco industrial consigam varrer todo o fundo, destruindo todo o recurso natural e pescando inclusive aquilo que não precisam.

Como dito anteriormente, como conseqüência da modernização houve uma aceleração na destruição dos recursos naturais, o que levou às políticas do setor pesqueiro a promoverem a aquicultura (CARDOSO, 2001).

A política "Mais pesca e aquicultura" que no litoral norte do Paraná se identifica pela iminência da instalação das três áreas aquícolas - como citado anteriormente, já cedidas pelos próximos vinte anos à ONG Instituto Mar e Vida - implica a privatização do território de uso comum dos pescadores artesanais. Isso significa que além da privatização da terra, privatiza-se também o mar, impedindo-se assim a reprodução da vida dos pescadores e pescadoras artesanais da Vila do Superagüi.

Entende-se neste sentido, que os territórios de vida dos pescadores e pescadoras da Vila do Superagüi, assim como da maioria dos pescadores artesanais, não se restringe à terra, já que parte de suas atividades produtivas acontecem no mar. Os pescadores/as artesanais têm lógicas territoriais de relação estreita entre a água e a terra. $\mathrm{Na}$ água (rio, mar ou mangue), eles/as desempenham a atividade da extração do pescado e na terra têm suas moradias, os espaços de beneficiamento do pescado para venda e espaços para alimentação (CARDOSO, 2009).

O território é entendido aqui como um "espaço definido por e a partir de relações de poder" (SOUZA, 2009, p. 59). A lógica territorial e essas especificidades identitárias dos pescadores/as artesanais entram em conflito com o Estado a partir da implantação arbi- 
traria das políticas públicas de desenvolvimento nos territórios dos pescadores/as artesanais. O território é disputado por usos diferentes implicando em relações desiguais de poder que geram o avassalamento e, portanto, a impossível convivência entre a pesca industrial e os pescadores artesanais; as políticas de desenvolvimento pesqueiro e a vida dos pescadores e pescadoras artesanais. Nos territórios de dos pescadores e pescadoras artesanais da Vila do Superagüi não somente se realizam as atividades produtivas, mas se reproduz a vida sendo que devido a esses conflitos se vêm afetados os modos de viver específicos e, assim, nega-se a própria vida dessa comunidade.

\section{RESISTÊNCIAS DOS PESCADORES E PESCA- DORAS ARTESANAIS MEDIANTE O MOVI- MENTO SOCIAL}

A representação dos pescadores, até a promulgação da Constituição Federal (CF) de 1988 estava vinculada diretamente às colônias representadas em setores, federações estaduais e à confederação nacional, ligadas todas ao Estado. Mas a luta dos pescadores artesanais propiciou a instauração do art. 8 da CF desvinculando as colônias de pesca da Marinha, o que foi um grande passo para os pescadores, no sentido de permitir sua organização sem interferência do Estado. "Este momento pode ser considerado um marco no processo de mobilização e politização contemporânea da categoria dos trabalhadores da pesca" (CARDOSO, 2009, p. 9).

Apesar disso, no contexto da Vila do Superagüi, os pescadores e pescadoras artesanais não se sentem acolhidos pela colônia e, por isso, em 2008 formam o movimento social dos pescadores e pescadoras artesanais - MOPEAR. A organização do movimento se inicia durante e a partir do processo de realização do fascículo da Nova Cartografia Social dos Povos e Comunidades Tradicionais, ao enxergarem de forma mais sistematizada os conflitos nos seus territórios. $\mathrm{O}$ processo de realização durou em torno de oito meses nos quais a comunidade se reunia, discutia diversas questões relativas às formas de organização da comunidade (infraestrutura, circulação, legislação, direitos), práticas sociais (autoafirmação coletiva, identidade e os limites impostos para sua reprodução por deter- minadas políticas públicas), os conflitos no território (conflitos socioambientais) e as possíveis formas de resistência. É dentro desse contexto que eles e elas reivindicam suas lutas perante os órgãos do Estado buscando garantir o direito de uso dos territórios de pesca e suas artes específicas na atividade.

Uma das ações do MOPEAR é a tramitação na Câmara de Vereadores de Guaraqueçaba de uma lei municipal relacionada aos pescadores artesanais para que suas práticas sejam consideradas como patrimônio imaterial. Pelo fato de terem práticas socioculturais específicas e diretamente ligadas aos seus territórios, os pescadores e pescadoras artesanais da Vila do Superagüi se autodenominam comunidade tradicional, desta maneira, eles poderiam iniciar um processo de reconhecimento de seus territórios tanto na terra como no mar e a manutenção de suas práticas produtivas, como é a arte da pesca artesanal.

O MOPEAR também está avaliando a possibilidade de criação de uma reserva extrativista pesqueira (Resex Marinha) ou de um acordo de pesca para ter uma área exclusiva para a comunidade. Essa questão ainda está em processo de decisão, já que como ambas as propostas estariam dentro dos limites da área de amortecimento do Parque Nacional do Superagüi é necessário avaliar qual das duas categorias seria mais viável de ser apresentada ao ICMBio para negociação.

\section{CONSIDERAÇÕES SOBRE OS PESCADORES E PESCADORAS ARTESANAIS EM UM CON- TEXTO DE EXPROPRIAÇÃO}

Como afirmado anteriormente, os pescadores e pescadoras artesanais da Vila do Superagüi, que já sofrem restrições de uso e ocupação de parte dos seus territórios, em terra, devido à instalação do Parque Nacional do Superagüi, passaram a se especializar na atividade da pesca. Essa especialização implica na mudança do modo de vida da comunidade, negando assim, o trabalho realizado pela combinação caça-pesca-agricultura.

Isso, aliado à identificação de que as políticas públicas de pesca são propostas especialmente para a pesca industrial, fazendo com que os pescadores precisem comprar novos equipamentos, se endividem e tenham de aprender outra forma de pescar, provoca 
Políticas de desenvolvimento da pesca e a aquicultura: Conflitos e resistências nos territórios dos pescadores e pescadoras artesanais da Vila do Superagüi, Paraná, Brasil

Mercedes Solá Pérez, Jorge Ramón Montenegro Gómez

que os pescadores artesanais sejam obrigados a modificar as suas práticas produtivas e as suas formas de ser/fazer/reproduzir a vida. Ao mesmo tempo, as políticas públicas de incentivo à aqüicultura, neste caso das baías das Laranjeiras e dos Pinheiros, geram a privatização de áreas do mangue retirando a possibilidade de autonomia na pesca e captura de ostras.

A aquicultura, tida como alternativa de emprego e renda ao trabalho autônomo do pescador artesanal ajusta-se a uma racionalidade industrial que limita a compreensão dos fatores ecossistêmicos imbricados, os quais possibilitam ao pescador uma diversidade de interações com o meio, objetivando manter e recriar seu espaço de trabalho. Ao trabalhar de forma artesanal, o pescador utiliza-se da forma autônoma dos meios de produção e do conhecimento tradicional do saber sobre a natureza, seus ciclos e no manejo das técnicas sustentáveis de captura. Dessa forma, a aqüicultura nega o saber tradicional, os conhecimentos, as artes de pesca e as relações de partilha sociais (MENDONÇA, VALENCIO, 2008).

A vida dos pescadores e pescadoras artesanais da Vila do Superagüi, seguindo o ideal de desenvolvimento capitalista que rege nossa sociedade é desprezado e considerado como atrasado. A hierarquia, a tecnologia, a modernidade e o progresso que caracterizam esse desenvolvimento seriam, em contraposição, o único caminho do aparente sucesso (SANTOS, 2006). A criação de políticas públicas impõe esse ideal, que negam a existência de outras racionalidades não capitalistas, ocidentais e modernas.

As políticas públicas da pesca no contexto da SUDEPE, da SEAP/PR ou do MPA trazem esse viés da modernização, do progresso, do desenvolvimento. Isto significa que se estabelecem novas relações e tecnologias para o setor pesqueiro sem considerar o saber e o fazer tradicional (MENDONÇA, VALENCIO, 2008). As comunidades tradicionais e os seus conhecimentos são tratados como descartáveis (SANTOS, 2006).

A apropriação privada (neste caso por uma ONG) de áreas aquícolas e o avanço da pesca industrial são formas atuais de apropriação e pilhagem da natureza em função da continuação da acumulação capitalista, caracterizada pela espoliação (HARVEY, 2004). Parece evidente que o modelo agroexportador se reproduz em todas as esferas (também no setor pesqueiro), com base na acumulação por espoliação, isto é, a natureza transformada em recursos naturais (PORTO-GONÇALVES, 2006) e apropriada por uma racionalidade científica moderna buscando a reprodução do modelo capitalista em detrimento da reprodução da vida dos pescadores artesanais da Vila do Superagüi.

A política de mercantilização de todas as esferas da vida se aprofunda com a estratégia da privatização dos serviços estatais e abertura da economia a partir de desregulamentação do mercado da época neoliberal, "tornando o Estado uma espécie de refém do novo poder econômico centrado nas multinacionais produtivas e financeiras" (OLIVEIRA, 2007, p. 31). O neoliberalismo promoveu a privatização da maioria dos serviços públicos sociais como saúde, educação, previdência, etc. Ao converter tudo isso em mercadoria e, portanto, plausível de ser comercializada e manejada pelo poder privado, propicia-se um novo momento de acumulação de capital através da comercialização desses serviços e se instaura o fim do Estado de bem-estar. Somado a isso, a disciplina fiscal e monetária, a continuação da exploração de matérias-primas a partir de megaprojetos e as políticas sociais assistencialistas, possibilitam a reprodução do capital. Isto é, permitem o aprofundamento da acumulação pela via da espoliação (HARVEY, 2004), mercantilizando-se todas as esferas da vida e negando os direitos das comunidades locais.

A acumulação por espoliação a que Harvey (2004) faz referência é a apropriação injusta da natureza por parte dos órgãos gestores das políticas públicas em prol de interesses privados, especialmente externos, e de um modelo de desenvolvimento alheio à reprodução da vida nos territórios antes públicos, comunais. Na Vila do Superagüi, o conceito de acumulação por espoliação se identifica pela imposição das políticas de modernização do setor pesqueiro que geram a privação de uso do território pelas comunidades, promovendo o avanço da pesca industrial e a progressiva instalação de áreas aquícolas industriais.

Privatiza-se a vida e as decisões políticas passam pelo crivo ou, inclusive, são executadas por agentes externos à escala local que não procuram a reprodução da vida senão a reprodução do capitalismo e o enriquecimento individual. 
Essas políticas provocam, portanto, mudanças na lógica do trabalho, da produção, do modo de apropriação dos territórios e, portanto, da reprodução da vida dos pescadores artesanais do Superagüi. São políticas promovidas nacionalmente pelo Ministério de Pesca e Aqüicultura e internacionalmente pela FAO e têm lógicas alheias à lógica de reprodução local, já que respondem a interesses externos como é a expansão da exploração dos recursos dentro de uma reprodução ampliada do capital, mas com um discurso de garantir a segurança alimentar. Para isso, as políticas se voltam para a industrialização do setor, especialmente de aquicultura devido a que os estoques de peixes estão em diminuição e porque a criação de peixes em áreas aquícolas possibilita a modificação genética (MEIRELLES, QUEIROZ, 2010) promovendo assim mais uma forma de mercantilização e apropriação da natureza.

Segundo o relatório de aquicultura da FAO, o potencial de crescimento deste subsetor é enorme já que há muitas áreas plausíveis de serem exploradas e investidores interessados. Isso permitiria maiores possibilidades de emprego e segurança alimentar, sempre que seja incentivado o consumo de pescado (FAO, 2011). Isso traz como conseqüências a intensificação até a exaustão do recurso pesqueiro, a modificação das condições ambientais das áreas onde se localiza a aqüicultura e a privatização desses territórios pela desapropriação do uso comunal para uso industrial. Por sua vez, isso provoca uma maior marginalização dos sujeitos que moram no local, já que as áreas de aquicultura estão sendo cedidas a ONGs, ou seja, planejadas como parques aquícolas industriais não somente negando o modo de reprodução do pescador artesanal, mas também piorando as condições de concorrência com o subsetor industrial e promovendo um processo de assalariamento ou expulsão implícita do território dos pescadores do Superagüi.

Ou seja, segundo a FAO as áreas aquícolas são fonte de segurança alimentar mundial, mas o que de fato estão promovendo é o uso de pacotes tecnológicos, de agrotóxicos e espécies exóticas; a expropriação dos recursos e territórios dos pescadores artesanais e a falta de soberania e segurança alimentar para as comunidades que vivem próximas às áreas. Isso significa dizer que se mercantilizam e privatizam a terra e o mar pela restrição de usos, pelos incentivos ao uso de tecnologias cujo acesso é através de créditos e endividamentos permanentes e se negam formas produtivas diferenciadas, negando assim a própria vida dos sujeitos das comunidades de pescadores artesanais.

Observa-se que é indispensável a organização da comunidade para a luta contra este modelo de avassalamento que é o modelo de desenvolvimento do capital. Mas, apesar disso, há poucas respostas por parte dos órgãos públicos como ICMBio, MPA ou mesmo a Prefeitura Municipal diante das solicitações dos pescadores, como o pedido de lei de patrimônio imaterial ou a demanda de figuras de proteção alternativas que permitam garantir seus recursos pesqueiros.

A organização social aliada às emergências identitárias traz novas perspectivas de enxergar possibilidades de enfrentamento ao sistema capitalista. Nesse sentido, é necessário o aprofundamento de ações para reprodução da vida que já existem concomitantemente e apesar dos dominadores (CECEÑA, 2010). É já um fato que há uma organização "desde abaixo" dos movimentos sociais em América Latina que contestam os processos perversos do capital (ZIBECHI, 2008). Assim pode-se dizer que, pensar autonomamente, olhando desde uma perspectiva emancipatória e afirmando a vida, reproduzir a vida a partir de lógicas não mercantilistas, consumistas e depredadoras; já são práticas que carregam uma crítica profunda contra esse sistema que difunde a barbárie.

\section{AGRADECIMENTOS}

O texto resulta de pesquisa de mestrado da primeira autora, realizada com apoio da Coordenação de Aperfeiçoamento de Pessoal de Nível Superior, Capes, Brasil. Os autores agradecem à Maximiliano Repeto pelo auxílio na versão em inglês do resumo. 
Políticas de desenvolvimento da pesca e a aquicultura: Conflitos e resistências nos territórios dos pescadores e pescadoras artesanais da Vila do Superagüi, Paraná, Brasil

Mercedes Solá Pérez, Jorge Ramón Montenegro Gómez

\section{REFERÊNCIAS}

ALMEIDA, A. W. de. Conceito de Terras Tradicionalmente Ocupadas. (Seminário Sobre Questões Indígenas) 2005. Disponível em: $<$ www.redeagu.agu. gov.br>. Acesso em 23 out. 2010.

ANDRIGUETTO F ${ }^{\circ}$, J. M. Sistemas técnicos de pesca e suas dinâmicas de transformação no litoral do Paraná, Brasil. Tese de doutorado em Meio Ambiente e Desenvolvimento, UFPR, 1999.

BORGES, J. A institucionalização da pesca no Brasil entre 1912 a 1989. 2007. Disponível em: < http://www.webartigos.com/artigos/a-institucionaliza-ccedil-atilde-o-da-pesca-no-brasil-entre-1912-a-1989/2276/>, acesso em 3 mar. 2011.

CARDOSO, E. S. Trabalho e Pesca - Apontamentos para a investigação. Revista Pegada Eletrônica, v. 10, p. 1-14, 2009.

CARDOSO, E. S. Pescadores artesanais: Natureza, território, movimento social. Tese de Doutorado em Geografia. São Paulo: USP, 2001.

CECEÑA, Ana Esther. Dominar la naturaleza o Vivir Bien: disyuntiva sistémica. $3^{\text {a }}$ CONFERENCIA SOBRE LA CRISIS DE LA SOCIEDAD CAPITALISTA Y LOS CAMINOS QUE SE ENSAYAN PARA SU SUPERACIÓN. 2010. Anales... Disponível em: <www.geopolitica.ws> Acesso em 18 dez. 2010.

CORRÊA, M. F. M. Pesca no litoral do Paraná, 2003. Disponível em: <

http://www.labictio.bio.br/> Acesso em 15 jun. 2011.

ESTEVA, G. Desenvolvimento. In: SACHS, W. Dicionário do desenvolvimento: Guia para o conhecimento como poder. Petrópolis: Vozes, 2000.

FAO - FOOD AND AGRICULTURE ORGANIZATION. Aquacultura tem potencial para combater a pobreza e a insegurança alimentar. 2011. Food and Agriculture Organization. (Sítio na internet). Disponível em: $<$ http://www.onu.org.br/fao-aquacultura-tem-potencial-para-combater-a-pobreza-e-inseguranca-alimentar/> Acesso em Nov. 2011.
HARVEY, D. O novo imperialismo. São Paulo: Loyola, 2004.

IHU - INSTITUTO HUMANITAS. A reorganização do capitalismo brasileiro, 2009. Instituto Humanitas (Unisinos) (sítio na internet). Disponível em: $<$ http:// www.ihu.unisinos.br/index.php?option=com_noticia s\&Itemid $=18 \&$ task $=$ detalhe $\& i d=27407>$ Acesso $\mathrm{em}$ 20 jan 2010.

LATOUCHE, S. Sobrevivir al desarrollo: De la descolonización del imaginario económico a la construcción de una sociedad alternativa. Barcelona: Icaria, 2007.

LEFF, E. Saber ambiental: sustentabilidade, racionalidade, complexidade, poder. Petrópolis: Vozes, 2001.

LOBO COSTA, A. Alguns aspectos sobre a pesca artesanal no Brasil. 2007. International Collective in Suporte of Fisherworks (sítio na internet). Disponível em:

$<$ http://www.icsf.net/icsf2006/jspFiles/cedepesca/ presentaciones/lobocostas/lobocosta.doc $>$ Acesso em: 12 jun. 2011.

MEIRELES, A. J. de A; QUEIROZ, L. de S. A monocultura do camarão: danos socioambientais à base da vida comunitária tradicional no litoral do Nordeste brasileiro. In: ZHOURI, A; LASCHEFSKI, K. (org.). Desenvolvimento e conflitos ambientais. Belo Horizonte: UFMG, 2010. p.1-14.

MENDONÇA, S. A. T. de; VALENCIO, N. F. L. da S. $O$ papel da modernidade no rompimento da tradição: As políticas da SEAP como dissolução do modo de vida da pesca artesanal. Boletim do Instituto de Pesca, São Paulo, 34(1), p.107-116, 2008.

MPA - MINISTÉRIO DE PESCA E AQÜICULTURA. Mais Pesca e Aqüicultura. Plano de Desenvolvimento Sustentável: Uma rede de ações para o fortalecimento do setor. Disponível em: $<$ http://www.mpa.gov. $\mathrm{br} / \mathrm{mpa} / \mathrm{seap} / \mathrm{html} / \mathrm{Plano} \% 20 \mathrm{de} \% 20$ Desenvolvimento/ Cartilha_EAP_final.pdf $>$ Acesso em 1 abr. 2011. 
MPA - MINISTÉRIO DE PESCA E AQÜICULTURA. Potencial brasileiro. Disponível em: $<\mathrm{http}: / /$ www.mpa.gov.br/\#aquicultura/informacoes/potencial-brasileiro> Acesso em 2 mar. 2011.

MPA - MINISTÉRIO DE PESCA E AQÜICULTURA. Territórios da Pesca e Aqüicultura. Disponível em: <http://www.mpa.gov.br/\#planos_e_politicas/ territórios $>$. Acesso em 18

Nov. 2011.

OLIVEIRA, F. de; RIZEK, C. S. (org.). A era da indeterminação. São Paulo: Boitempo, 2007.

PORTO-GONÇALVES, C. W. A globalização da natureza e a natureza da globalização. Rio de Janeiro: Civilização Brasileira, 2006.

SANTOS, B. de S. Renovar la teoría crítica y reinventar la emancipación social: encuentros em Buenos Aires. Buenos Aires: CLACSO, 2006.

SILVA, L. G. Caiçaras e jangadeiros: Cultura marítima e modernização no Brasil (1920-1980). São Paulo: NUPAB-USP, 2004.

SOUZA, M. L de. "Território" da divergência (e da confusão): em torno das imprecisas fronteiras de um conceito fundamental. SAQUET, M. A; ESPÓSITO, E. S. (orgs.) Territórios e territorialidades: teorías, processos e conflitos. São Paulo: UNESP, 2009. p.12-26.

SVAMPA, M; ANTONELLI, M. A. Hacia una discusión sobre la megaminería a cielo abierto. In: Minería transnacional, narrativas del desarrollo y resistencias sociales. Buenos Aires: Biblos. 2009.

VIVEKANANDA, G. Parque Nacional do Superagüi: a presença humana e os objetivos de conservação. Dissertação (Mestrado em Engenharia Florestal), UFPR: Curitiba, 2001.

ZIBECHI, R. Dibujando fuera de los márgenes: los movimientos sociales en la transformación sociopolítica en América Latina. Buenos Aires: La crujía, 2008. 